\title{
Regulação de Emoções na Pré-Adolescência e Influência da Conversação Familiar
}

\author{
Lídia Suzana Rocha de Macedo ${ }^{1}$ \\ Tania Mara Sperb \\ Universidade Federal do Rio Grande do Sul
}

\begin{abstract}
RESUMO - Esse estudo analisa a relação entre regulação de emoções no pré-adolescente e conversação familiar sobre emoções. Participaram do estudo 74 pré-adolescentes (10 a 13 anos) de famílias de classe média que formaram dois grupos, o que conversa sempre em casa e o que não tem esse costume. Para acessar a regulação de emoções foram usadas duas histórias com final aberto que permitiram comparar os grupos quanto às estimativas de duração de emoções e estratégias para regulá-las e à presença de reavaliações cognitivas. Há diferenças significativas na ocorrência de reavaliações cognitivas para lidar com a raiva, que surgiram apenas no grupo que costuma conversar. Os resultados sugerem que conversação familiar sobre emoções pode auxiliar a desenvolver habilidades diferenciadas para regular emoções.
\end{abstract}

Palavras-chave: regulação de emoções, pré-adolescência, conversação familiar

\section{Emotional Regulation in Preadolescence and the Influence of Family Conversation}

\begin{abstract}
In this study the relation between emotional regulation of the preadolescent and conversation regarding emotions in family setting is investigated. Seventy-four preadolescents $(10-13$ years old $)$ of middle class families participated in this study; they composed two groups: one that always conversed at home and one that did not have that habit. To access emotional regulation two open-ended stories were used to compare groups considering: the estimated duration of the emotion, the strategies used to regulate them, and the occurrence of cognitive re-evaluation. There are significant differences in the occurrence of cognitive re-evaluation to deal with rage, found only in the group that regularly had conversations. Results suggest that family conversation concerning emotions can enhance the development of differentiated abilities to regulate emotions.
\end{abstract}

Keywords: emotional regulation; preadolescence; family conversation

A vida cotidiana apresenta constantemente situações que obrigam a pessoa a lidar com suas emoções. Há eventos mais carregados emocionalmente do que outros, mas mesmo eventos simples do cotidiano são tonalizados emocionalmente (Fivush \& Kuebli, 1997). O desenvolvimento da habilidade para regular as próprias emoções é uma consequência da socialização, sendo essencial para que a criança possa aderir aos valores e padrões de convivência social (Grusec, 2002).

Diversas pesquisas constataram que a conversação sobre experiências emocionais entre os pais e a criança pequena tem uma função estratégica no desenvolvimento de sua habilidade para identificar, compreender e expressar emoções (Burch, Austin, \& Bauer, 2004; Dunn, Bretherton, \& Munn, 1987). Resultados de pesquisas têm mostrado que a criança desenvolve um modelo para avaliar sua experiência, aprende a lidar com as emoções que a acompanham e desenvolve uma compreensão sobre si mesma durante o relembrar conjunto com seus pais das experiências vividas por ela (Fivush, 1991, 2007; Fivush, Haden, \& Reese, 2006). Há, no entanto, poucas informações disponíveis sobre os possíveis efeitos dessas conversações na regulação de emoções em etapas posteriores, como na pré-adolescência.

1 Endereço para correspondência: Universidade Federal do Rio Grande do Sul - Avenida Nilo Peçanha $n^{\circ} 2715$ apt. 202. Porto Alegre, RS. CEP 91330-001.E-mail: lidiasrmacedo@gmail.com
A pré-adolescência é o período mais indicado para ser abordado por programas de prevenção e promoção de saúde, uma vez que os comportamentos que comprometem a saúde ainda não se iniciaram ou são mais fáceis de mudar, como recomenda a Organização Pan-americana da Saúde (OPAS) (Breinbauer \& Maddaleno, 2005). Pré-adolescência, conforme a OPAS, refere-se à faixa etária de 9 a 12 anos em meninas e de 10 a 13 anos em meninos. No Brasil, a faixa dos 9 aos 13 anos é predominantemente investigada por profissionais da medicina/enfermagem e ainda pouco investigada na psicologia, como mostra a busca, realizada pelas autoras em 9 de maio de 2012, pelo termo pré-adolescência na Biblioteca Virtual em Saúde (BVS), que revelou 8.135 resultados. O portal SciELO (biblioteca de revistas e artigos científicos brasileiros) apresentou apenas quatro resultados e o portal de Periódicos Eletrônicos de Psicologia (PePsic), um resultado. A adolescência é um período de desenvolvimento mais investigado, com 1.567.833 resultados na BVS. Justifica-se porque é um grupo etário vulnerável e de risco para a depressão, transtornos de conduta, transtornos alimentares, drogas e violência, como mostra uma revisão das publicações brasileiras sobre saúde mental na adolescência (Benetti, Ramires, Schneider, Rodrigues, \& Tremarin, 2007). No entanto, o início de alguns transtornos mentais tem ocorrido antes desse período. Depressão, por exemplo, tem ocorrido cada vez mais cedo (Bahls \& Bahls, 2002). Assim, é necessário intensificar as investigações na pré-adolescência, para que se possa criar e implementar práticas preventivas. 
Observa-se, ainda, que durante a adolescência, o relacionamento com pares e amigos, juntamente ao relacionamento com os parceiros românticos, se transforma no determinante mais forte do valor do self (Shaffer \& Kipp, 2009). Esse processo é acompanhado de um afastamento natural do núcleo familiar (Wagner, Falcke, Silveira, \& Mosmann, 2002). Já na pré-adolescência, apesar de se verificar um aumento da influência dos pares e amigos sobre a maneira de ser e de compreender as experiências (Breinbauer \& Maddaleno, 2005), a família ainda exerce uma influência predominante. É possível que a maneira de regular emoções do pré-adolescente receba influência da família, se ele tem o hábito de compartilhar e relembrar suas experiências em casa.

\section{Regulação de Emoções e Estratégias de Regulação}

Processos de regulação de emoções são comportamentos, habilidades e estratégias que podem ser conscientes ou inconscientes, automáticos ou controlados por esforço, e que servem para modular, inibir ou incitar a experiência e a expressão emocional (Gross \& Thompson, 2007). Regular emoções envolve mudanças na dinâmica da emoção, o que inclui o tempo que a emoção leva para emergir, a magnitude, a duração e um conjunto de respostas nos domínios fisiológico, do comportamento ou da experiência (Calkins \& Hill, 2007). Emoções podem ser interrompidas e submetidas ao controle por ação da própria pessoa (autorregulação) ou de outros.

Concebida como um processo, a regulação da emoção pode dar-se em momentos distintos, se considerada como ponto inicial a situação que provocou ou tem potencial de provocar emoções. Para Gross (1998), a emoção pode ser regulada por meio de: seleção da situação (ação em antecipação à situação), modificação da situação (ação sobre a situação), investimento da atenção (retirar a atenção da situação), mudança cognitiva (mudar o significado da situação) e modulação de resposta (tentar influenciar a resposta fisiológica, experiencial ou comportamental).

A utilização de estratégias para regular emoções tem sido investigada com relação ao seu custo e benefício em diversas pesquisas (Gross, Richards, \& John, 2006; Mauss, Cook, Cheng, \& Gross, 2007; Schore, 2001). Gross e Thompson (2007) analisam vantagens e desvantagens, e requisitos de alguns tipos de estratégias para regular emoções. A seleção de situação (e.g., aproximar-se ou evitar pessoas, lugares ou atividades) exige habilidades cognitivas de abstração para imaginar e construir possibilidades futuras e inclui a possibilidade de um viés, porque as pessoas tendem a subestimar suas respostas emocionais a cenários futuros e a superestimar a duração de suas respostas negativas para as mais variadas situações. Modificar a situação (e.g., quando para evitar responder agressivamente a uma provocação, a pessoa decide deixar o local) nem sempre é uma opção possível. Dentre os tipos de investimento de atenção, a distração é o primeiro processo regulatório da atenção a aparecer, mas usado toda a vida, sobretudo quando não é possível modificar a situação. Pode-se dirigir a atenção para dife- rentes aspectos da situação, retirar inteiramente a atenção da situação ou ainda mudar internamente o foco da atenção (e.g., quando a pessoa pensa ou lembra coisas que lhe agradam para afastar a emoção). Concentração pode ter efeitos paradoxais: dirigir repetidamente a atenção para os sentimentos e suas consequências pode levar à ruminação; manter o foco nas possíveis consequências ameaçadoras da situação faz com que a ansiedade aumente, ainda que haja diminuição da intensidade das respostas à emoção negativa original. Mudança cognitiva pressupõe a habilidade para avaliar a situação em que se está com a finalidade de alterar seu significado emocional, seja mudando a maneira de pensar sobre a situação ou sobre a própria capacidade de lidar com as demandas que ela impõe. Modulação da resposta implica aquisição de um autocontrole eficiente, como por exemplo, quando a pessoa se concentra em sua respiração alterada e em sua postura tensa, buscando um relaxamento corporal que lhe ajude a lidar com a emoção (Gross \& Thompson, 2007).

Em resumo, seleção de situação, mudança cognitiva e modulação da resposta são consideradas eficazes, mas possuem pré-requisitos no âmbito do desenvolvimento, tais como pensar de modo abstrato e ter adquirido maturidade emocional que permita exercer autocontrole. Modificação da situação depende de condições externas. Dentre os investimentos da atenção, a concentração também requer desenvolvimento cognitivo e emocional, mas pode levar à ruminação ou aumento de ansiedade, enquanto a distração é um recurso disponível desde cedo na criança.

Há um tipo de mudança cognitiva que tem sido especialmente investigado: a reavaliação cognitiva. Esta ocorre quando é designado um significado não emocional ao evento, de modo a modificar seu impacto emocional (Gross et al., 2006). A reavaliação cognitiva é uma estratégia que oferece dupla vantagem: ao reavaliar a situação que provocou a emoção, a experiência subjetiva de desconforto da pessoa diminui, cessando a necessidade de esforços de autorregulação, e recursos cognitivos como a memória ficam disponíveis (Schore, 2001).

Mauss et al. (2007), por exemplo, compararam, em uma pesquisa experimental, mulheres adultas com altos e baixos escores na subescala de reavaliação cognitiva (EQR), mediante uma situação que provocava raiva, em que se mediram suas respostas cardiovasculares. $\mathrm{O}$ grupo com escores elevados em reavaliação cognitiva apresentou um perfil mais adaptativo de experiência emocional, com menos raiva e emoções negativas e mais emoções positivas, e melhores respostas cardiovasculares (melhor desempenho cardíaco e contratibilidade ventricular, e menos resistência periférica total).

A reavaliação cognitiva, portanto, é efetiva ao administrar a experiência afetiva, diminuindo a experiência subjetiva de desconforto da pessoa, tem um custo psicofisiológico menor e permite que os recursos cognitivos fiquem disponíveis. Não foram encontradas informações acerca do uso de reavaliações cognitivas para regular emoções em pré-adolescentes, porém há indícios de que, ao longo do desenvolvimento, diferentes escolhas de estratégias para regular emoções são efetuadas. 


\section{Regulação de Emoções no Desenvolvimento: Possíveis Influências}

Pesquisas brasileiras analisaram a forma como os conceitos sobre emoções se organizam e se estruturam (Roazzi, Dias, Silva, Santos, \& Roazzi, 2011) e examinaram estratégias de regulação de emoções utilizadas em crianças e pré-adolescentes (Cruvinel \& Boruchovitch, 2011; Dias, Vikan, \& Gravas, 2000; Oliveira, Dias, \& Roazzi, 2003; Pavarini, Loureiro, \& Souza, 2011; Santos, 2005). Pavarini et al. (2011) verificaram, em crianças de 8 a 11 anos, que o conhecimento de estratégias de regulação emocional podem torná-las menos propensas a reações impulsivas e defensivas. No estudo de Roazzi et al. (2011), observou-se que meninos e meninas ( 7 a 12 anos) compartilhavam o mesmo campo semântico relativo às emoções, o que significa que o gênero não interferiu na maneira de compreender as emoções. Esse resultado oferece uma explicação possível para a ausência de diferenças relacionadas ao gênero constatadas em outras pesquisas brasileiras que investigaram a regulação de emoções (Dias et al., 2000; Macedo, 2011; Oliveira et al., 2003). Sabe-se, no entanto, que a maneira de compreender emoções, e a decorrente escolha de estratégias de regulação, sofre influência da cultura (Dias et al., 2000); do momento histórico e da classe social em que a pessoa está inserida (Roazzi et al., 2011); do contexto em que ocorre a situação que evoca a emoção (Santos, 2005); e da idade (Dias et al., 2000; Roazzi et al., 2011; Santos, 2005). A ação dessas influências e diferenças metodológicas podem explicar porque diferenças de gênero aparecem em algumas pesquisas e não em outras.

Quanto às diferenças culturais, Dias et al. (2000) compararam crianças de 5 a 9 anos de idade, brasileiras e norueguesas, com respeito ao uso de estratégias para regular as emoções de tristeza ou raiva. Enquanto as crianças brasileiras mostraram preferência por buscar a ajuda dos pais para lidar com as duas emoções, as crianças norueguesas preferiram buscar o apoio social dos amigos.

Com relação ao nível socioeconômico, Roazzi et al. (2011) verificaram que este pode influenciar a maneira como a criança representa suas emoções. Os autores utilizaram a distinção que Damasio (2004) faz entre emoção e sentimento. Sentimento é a representação mental do corpo funcionando de certa maneira, enquanto emoção é uma coleção de respostas químicas e neurais que forma um padrão específico, o que ocorre quando o cérebro detecta um estímulo capaz de evocar emoções. Os resultados mostraram que crianças de escola particular equivaleram emoção a sentimento, diferente do que ocorreu com as crianças de escola pública, de nível socioeconômico mais baixo. Em suas associações livres, emoções estiveram relacionadas à tristeza, mas ao falarem das próprias emoções, fizeram mais associações com alegria. Os autores entendem que as crianças da escola particular perceberam as peculiaridades das emoções, diferente do que aconteceu com as crianças de escola pública.

O contexto também pode interferir na escolha de estratégias de regulação de emoções. Santos (2005) investigou o uso de estratégias de regulação de emoções em crianças de 6 aos 10 anos, diante de situações fictícias envolvendo medo, em dois contextos: ameaça à integridade física e ameaça social. Esta se referia à possibilidade de um desempenho ruim diante de outros na escola. No contexto de ameaça à integridade física, a estratégia de interação social foi a mais frequente, diferente do contexto de ameaça social, em que a distração foi a mais frequentemente citada.

Também a idade influencia a maneira de compreender as emoções e a escolha de estratégias para lidar com elas. Roazzi et al. (2011) analisaram a forma como os conceitos sobre emoções se organizam e se estruturam ao longo do desenvolvimento (7 a 12 anos). Os resultados indicam que a idade influencia: a) a formação de conceitos para emoções, que ficam mais elaborados; b) a vivência das emoções que passam a ser percebidas de forma mais diferenciada, o que se observa no aumento de associações livres para emoções como felicidade, amor e tristeza; c) a frequência em que emoções negativas são mencionadas, o que sugere que essas passam a receber mais atenção. Quanto ao desenvolvimento de estratégias, entre 4 e 5 anos, a maioria das crianças propõe estratégias de regulação de emoção para tristeza e raiva, e dos 5 aos 9 anos, diminui a frequência de respostas consideradas não funcionais (e.g., não sei) e aumenta a frequência de estratégias cognitivas (e.g., não levar os fatos tão a sério) (Dias et al., 2000). Dos 6 aos 10 anos, Santos (2005) constatou que o raciocínio sobre emoções se torna mais complexo, calcado na experiência e na inferência, pois a criança vai se tornando mais capaz de perceber seus sintomas fisiológicos e os avaliar cognitivamente.

Características próprias do desenvolvimento também podem influenciar o pré-adolescente em sua maneira de lidar com as emoções. O desenvolvimento cognitivo na pré-adolescência permite pensar de modo abstrato e formular hipóteses, em função da entrada na fase das operações formais (Piaget, 1972), um requisito fundamental para realizar reavaliações cognitivas. Fazer reavaliações cognitivas também envolve um autocontrole eficiente, pois o pré-adolescente irá substituir uma resposta imediata (e.g., distrair-se), por outra que resulta de um processo reflexivo.

Estudos que têm trabalhado com adolescentes mostram que nesse período que se segue à pré-adolescência pode haver dificuldades para regular a tristeza e a raiva (Baptista \& Oliveira, 2004; Formiga, 2004; Formiga, Cavalcante, Araújo, Lima, \& Santana, 2007; Reppold \& Hutz, 2003; Soares, Almeida, Coutinho, \& Mari, 1999). Assim, a depressão, por exemplo, ocorre três vezes mais em adolescentes do que em adultos (Soares et al., 1999). A depressão está negativamente associada à percepção de suporte familiar (Baptista \& Oliveira, 2004). Reppold e Hutz (2003) constataram que adolescentes com diagnóstico provável de depressão $(5,9 \%$ da amostra) reportaram baixa responsividade parental. A regulação da raiva em adolescentes também foi investigada em duas pesquisas brasileiras. Formiga et al. (2007) verificaram que o comportamento agressivo físico e verbal, de raiva e hostilidade, está positivamente relacionado à predisposição do adolescente em buscar sensações de novidade e intensidade. Formiga (2004) constatou que há uma relação inversa entre as condutas antissociais e delitivas e os indicadores positivos da relação familiar (compreensão, confiança, afeto).

Observa-se, portanto, uma aproximação entre relacionamento familiar e o desenvolvimento saudável ou não da 
habilidade para regular emoções. Ao investigar a depressão na adolescência, Reppold e Hutz (2003) chamaram a atenção para a necessidade de um espaço familiar para discutir os problemas cotidianos, com vistas a criar oportunidades para compreender os eventos estressores vivenciados. Considerando que a comunicação é um indicador da qualidade nos relacionamentos e um meio de aprimorá-los (Sillars, Canary, \& Tafoya, 2004), a presença desse espaço de conversação na família durante a pré-adolescência pode melhorar a qualidade do relacionamento familiar, o que funciona como um fator de proteção para o desenvolvimento dos filhos.

\section{A Função das Conversações Familiares sobre Experiências Envolvendo Emoções}

As conversações para relembrar experiências emocionalmente carregadas são especialmente importantes, porque apenas uma parte da interpretação e avaliação da emoção acontece enquanto o evento está sendo experimentado, sendo que a maior parte dá-se retrospectivamente (Fivush \& Kuebli, 1997). É especificamente no contexto do relembrar experiências emocionalmente carregadas que os pais fornecem uma estrutura para a criança desenvolver a compreensão de como e porque se vivencia cada emoção, um guia para interpretar e avaliar tipos específicos de experiências emocionais (Fivush \& Sales, 2002). Esse contexto favorece o desenvolvimento da habilidade para avaliar emoções e, mais importante, permite compreender o papel da avaliação na eliciação de cada emoção e, assim, compreender que as pessoas podem apresentar diferentes reações emocionais diante da mesma situação (Harris \& Lipian, 1989).

Em pré-adolescentes, a explanação parental de emoções, codificada nas narrativas compartilhadas sobre eventos familiares positivos e negativos, está associada às medidas do desenvolvimento da autoestima e do ajustamento emocional e comportamental do adolescente dois anos mais tarde (Bohanek, Marin, Fivush, \& Duke, 2006). Mães que elaboram e explicam emoções ao relembrar eventos estressantes têm pré-adolescentes que mostram estratégias de coping mais efetivas com menos problemas de internalização e externalização (Fivush \& Sales, 2006; Sales \& Fivush, 2005). Bohanek et al. (2006) verificaram que a expressão e explanação materna de emoções nas narrativas familiares estão associadas, de modo geral, à autoestima positiva e ao ajustamento de filhos e filhas, entre 9 e 12 anos. Conversar sobre as experiências carregadas emocionalmente produz efeitos positivos duradouros no desenvolvimento. Sales, Fivush, Parker e Bahrick (2005), por exemplo, verificaram que as crianças de 3 e 4 anos que utilizaram mais palavras descrevendo emoções positivas e que incluíram mais informações nas narrativas produzidas de dois à seis meses após um furacão devastador, tiveram menores escores de estresse pós-traumático aos 9 e 10 anos.

O contexto das conversações sobre experiências emocionais pode, portanto, favorecer o desenvolvimento da habilidade necessária para avaliar e reavaliar cognitivamente uma situação potencialmente provocadora de emoções. A pré-adolescência, por anteceder a adolescência, é um momento estratégico para prevenir possíveis problemas de regulação de emoções. A literatura mostra que, dentre as emoções, há uma preocupação maior com os efeitos nocivos da regulação ineficaz da tristeza e da raiva (Baptista \& Oliveira, 2004; Formiga, 2004; Formiga et al., 2007; Reppold \& Hutz, 2003; Soares et al., 1999).

Assim sendo, este estudo objetivou investigar a relação entre a frequência de conversação sobre emoções entre pais e filhos e a regulação de emoções de tristeza e raiva por parte do pré-adolescente. Esperava-se encontrar diferenças entre pré-adolescentes que costumam conversar sempre sobre suas experiências envolvendo emoções em casa e aqueles que não têm esse costume. Adicionalmente, como a pré-adolescência tem sido pouco contemplada nos estudos sobre emoção, pretendeu-se também trazer subsídios para suprir esta lacuna.

\section{Método}

\section{Participantes}

Os dois grupos participantes deste estudo constituem um recorte da amostra de uma pesquisa que investigou os hábitos conversacionais em 189 famílias de classe média, com um filho pré-adolescente de 10 a 13 anos. O critério para a classificação nos grupos foi a resposta do pré-adolescente à questão do questionário sobre comunicação familiar que investiga se ele costuma contar em casa as coisas que acontecem em sua vida. O grupo que conversa sempre (G1) é composto por 45 pré-adolescentes que responderam "sempre", 27 do sexo feminino e 18 do sexo masculino, tendo em média 12,2 anos. O grupo que não costuma conversar (G2) é constituído por 29 pré-adolescentes que responderam "raramente" $(n=25)$ ou "nunca" $(n=4), 13$ do sexo feminino e 16 do sexo masculino, tendo em média 11,7 anos.

\section{Instrumentos}

Os dados foram coletados mediante a apresentação de duas histórias com conteúdo que provoca emoções e com final aberto. Para selecionar histórias que evocassem tristeza e raiva, foi realizado um estudo piloto em que primeiro pediu-se a um grupo de pré-adolescentes que listassem coisas que deixam triste e outras que dão raiva. Com base nessas informações foram criadas e testadas duas histórias para cada emoção. A partir das respostas, buscou-se a história que melhor evocava a emoção requerida. Na narrativa que evoca tristeza, o personagem principal quebra a perna na véspera de uma situação decisiva, que para os meninos é uma partida de futebol e para as meninas é uma apresentação de balé. $\mathrm{Na}$ narrativa que evoca raiva, o personagem principal sofre uma injustiça cometida por colegas durante a aula, que para os meninos é a acusação de brincar com o globo terrestre como se fosse uma bola e para as meninas, uma colega que destrói propositadamente parte de seu material escolar. Ao final das histórias, o pré-adolescente responde por escrito perguntas sobre o que o personagem principal está sentindo; quanto tempo vai durar esse sentimento; o que ele pode fazer para se sentir melhor; e porque isso o faria se sentir melhor. Conforme Bruner (1997), o uso das histórias ou narrativas permite 
que o pré-adolescente atribua ao personagem motivos para as emoções e sentimentos. As respostas do pré-adolescente permitem obter uma medida projetiva de sua maneira de lidar com emoções e sua estimativa sobre a duração da emoção revela a concepção que ele tem da eficácia das estratégias que utiliza.

\section{Procedimentos}

Este estudo é parte de uma pesquisa mais ampla, aprovada pelo Comitê de Ética em Pesquisa do Instituto de Psicologia da Universidade Federal do Rio Grande do Sul. Pais e pré-adolescentes preencheram questionários sobre os hábitos conversacionais da família e assinaram seus respectivos termos de consentimento livre e esclarecido. $\mathrm{O}$ instrumento para investigar a regulação de emoções do pré-adolescente foi aplicado coletivamente na escola, levando em média 15 minutos.

As respostas dos pré-adolescentes foram classificadas quanto às estimativas para a duração das emoções dos personagens principais das histórias e às escolhas de estratégias, que vão desde aquelas que não exigem esforço intelectual até as que exigem um desempenho cognitivo mais sofisticado. A duração da emoção pode ser estimada em tempo determinado (e.g., até um mês), tempo determinado por uma condição (e.g., até tirar o gesso) e tempo indeterminado (e.g., muito tempo ou para sempre). Com o consentimento dos autores, foi adaptada a classificação das estratégias de regulação utilizada por Oliveira et al. (2003) em crianças de até 10 anos. Buscou-se identificar os processos mentais envolvidos nas estratégias, o que permitiu reduzir o número de estratégias (de 11 para 8) e distinguir os tipos de atenção (distração/ concentração). Após esse procedimento, as estratégias foram: 1) não sabe; 2) vingar-se; 3 ) distrair-se; 4) interação social; 5) agir de modo altruísta; 6) buscar ajuda adulta; 7) concentrar-se; 8) técnicas cognitivas. Em "vingar-se" incluem-se as respostas que enfatizam revide, humilhações e punições; em "distrair-se", as que descrevem o desvio da atenção para atividades ou ambientes que favoreçam a sensação de bem-estar; em "interação social”, aquelas que enfatizam a busca pelo conforto obtido com a presença de pessoas, como pais ou amigos, que darão suporte emocional ou com quem poderão conversar e desabafar; em "agir de modo altruísta" classificam-se comportamentos aprovados socialmente, como a abnegação em favor de outros (do time, da amiga); "buscar ajuda adulta" significa buscar a interferência direta de uma pessoa considerada mais capaz para resolver o problema; "concentrar-se" significa desviar a atenção do estímulo que provocou a emoção na direção de um estímulo específico, como técnicas de relaxamento (e.g., olhar para a parede, respirar fundo para ficar calmo) ou empenhar-se em uma atividade intelectual (e.g., estudar mais, treinar para melhorar o desempenho); "técnicas cognitivas" refere-se às formas de racionalização para controlar a emoção (e.g., pensar que aquilo não significa nada; que terá outras oportunidades, pensar positivo, que tudo vai melhorar). Depois dessa etapa, fez-se uma busca pelas respostas em que ocorreram reavaliações cognitivas, isto é, em que foram construídos novos significados para as situações que originaram as emoções (Gross et al., 2006).
Para o cálculo da fidedignidade, dois juízes cegos no que concerne ao grupo a que pertencia o pré-adolescente classificaram (em $20 \%$ da amostra), separadamente, as respostas dos pré-adolescentes referentes às estratégias para lidar com a tristeza e com a raiva e as ocorrências de reavaliações cognitivas. Eventuais diferenças entre eles foram resolvidas por um terceiro juiz. $\mathrm{O}$ índice utilizado entre os juízes foi calculado utilizando-se o coeficiente Kappa $(0,86)$. Para a análise dos dados, foram utilizadas estatísticas descritivas e inferenciais. Testes de associação qui-quadrado foram realizados para identificar eventuais diferenças entre os grupos quanto à duração das emoções, estratégias utilizadas para regular a tristeza e a raiva, e ocorrência de reavaliações.

\section{Resultados}

Os resultados obtidos pelos dois grupos (G1: que conversa sempre; G2: que não costuma conversar) foram comparados quanto aos parâmetros: estimativa de duração da emoção sentida pelo personagem principal nas duas histórias, tipo de estratégia de regulação de emoções utilizadas e ocorrência de reavaliações para as situações geradoras de tristeza e raiva. Como se observa na Tabela 1, o parâmetro que revelou diferenças altamente significativas entre os grupos foi a ocorrência de reavaliações cognitivas, na situação que provoca raiva, não tendo o $\mathrm{G} 2$ produzido reavaliações. Os demais parâmetros não revelaram diferenças significativas entre os grupos.

Diferenças qualitativas entre os dois grupos podem, porém, ser observadas em cada um dos parâmetros utilizados. A Tabela 2 mostra que se repete o mesmo padrão em cada grupo nas estimativas de duração para as duas emoções. Enquanto o G1 evidenciou preferência pela opção "tempo determinado por uma condição", o grupo 2 , mostrou preferência pela a opção "tempo determinado".

Os dois grupos escolheram estratégias distintas para regular a tristeza e a raiva, sugerindo que as duas emoções demandam estratégias diferentes. Como mostra a Tabela 2, para lidar com a tristeza, a opção por distrair-se foi a escolha de quase um terço dos pré-adolescentes dos dois grupos, seguida por técnicas cognitivas, agir de modo altruísta, interação social e buscar ajuda de adultos (somente no G1). Já para lidar com a raiva, as opções destacadas nos dois grupos foram buscar ajuda de adultos, agir de modo altruísta e distrair-se.

$\mathrm{O}$ tipo de argumento utilizado nas reavaliações da situação que evoca tristeza foi diferente nos dois grupos: o G1

Tabela 1. Comparações entre os Grupos Contrastantes

\begin{tabular}{lll}
\hline Parâmetros & \multicolumn{2}{c}{ Emoções } \\
& Tristeza & Raiva \\
\hline $\begin{array}{l}\text { Duração da } \\
\text { emoção }\end{array}$ & $\chi^{2}(2)=3,88 ; p=0,14$ & $\chi^{2}(2)=4,65 ; p=0,98$ \\
$\begin{array}{l}\text { Estratégias } \\
\text { de regulação }\end{array}$ & $\chi^{2}(6)=7,40 ; p=0,28$ & $\chi^{2}(7)=12,38 ; p=0,08$ \\
$\begin{array}{l}\text { Reavaliações } \\
\text { cognitivas }\end{array}$ & $\chi^{2}(1)=0,42 ; p=0,51$ & $\chi^{2}(1)=6,60 ; p<0,01$ \\
\hline
\end{tabular}


Tabela 2. Desempenho dos Dois Grupos por Parâmetro

\begin{tabular}{|c|c|c|c|c|c|}
\hline \multicolumn{2}{|c|}{ Parâmetros } & \multicolumn{2}{|c|}{ G1 (\%) } & \multicolumn{2}{|c|}{ G2 (\%) } \\
\hline & & tristeza & raiva & tristeza & raiva \\
\hline \multirow{3}{*}{$\begin{array}{l}\text { Duração } \\
\text { da emoção }\end{array}$} & Determinada & 29 & 24,5 & 44,8 & 44,8 \\
\hline & Condicional & 37,5 & 46,5 & 17,2 & 24,2 \\
\hline & Indeterminada & 33,5 & 29 & 38 & 31 \\
\hline \multirow[t]{8}{*}{ Estratégia } & Não sabe & 0 & 2 & 7 & 0 \\
\hline & Vingar-se & 0 & 2 & 0 & 3 \\
\hline & Distrair-se & 29 & 13 & 27 & 20 \\
\hline & $\begin{array}{l}\text { Interação } \\
\text { social }\end{array}$ & 15 & 6 & 10 & 17 \\
\hline & Altruísta & 15 & 31 & 15 & 17 \\
\hline & Ajuda adulta & 11 & 33 & 0 & 31 \\
\hline & Concentrar-se & 7 & 11 & 7 & 0 \\
\hline & Técnicas & 22 & 0 & 15 & 10 \\
\hline \multicolumn{2}{|c|}{ Reavaliações cognitivas } & 31 & 20 & 24 & 0 \\
\hline
\end{tabular}

Nota. G1: grupo que conversa sempre e G2: grupo que não costuma conversar.

utilizou argumentos mais complexos do que os produzidos no G2. No G1, um participante para se sentir melhor iria "Apoiar os amigos e assistir o jogo... E os amigos o apoiariam, dizendo que ele não estragou o jogo deles e ninguém o está culpando. Ele poderia assistir ao jogo, pois assim se sentiria parte do jogo, consolando-o". Já no G2, das sete reavaliações produzidas, cinco respostas seguem o script do torcedor no futebol: "Não vou jogar, mas vou torcer pelo meu time".

\section{Discussão}

A hipótese levantada neste estudo é de que haveria diferenças na maneira de regular emoções entre dois grupos de pré-adolescentes, o grupo que costuma conversar sempre sobre emoções em casa (G1) e o que não têm esse costume (G2). Dentre os parâmetros utilizados para comparar os grupos estimativa da duração de emoções, estratégias de regulação, e reavaliações cognitivas - foi a ocorrência de reavaliações cognitivas para lidar com a raiva que revelou diferenças estatisticamente significativas entre os grupos. Portanto, neste estudo, a reavaliação cognitiva de situações que envolvem raiva é a aprendizagem que se mostrou estar significativamente relacionada ao contexto de conversação familiar.

Uma explicação possível para a ocorrência de diferenças entre os grupos nas reavaliações de situações que envolvem raiva, mas não nas situações que envolvem tristeza, é a interferência de peculiaridades na regulação dessas duas emoções.
É possível, por exemplo, que em famílias desse segmento social manifestações de raiva recebam mais atenção parental pelo risco potencial que trazem ao ambiente social e à manutenção dos relacionamentos (Markus \& Kitayama, 1991). Já a tristeza, uma vez que a criança tenha adquirido a capacidade de evitar o choro, pode passar mais facilmente despercebida no ambiente e por isso receber menos atenção parental, o que acaba por reforçar a opção por uma estratégia interna de regulação, ao invés de buscar a ajuda dos adultos próximos.

A diferença entre os dois grupos quanto ao emprego de reavaliações cognitivas para lidar com a raiva sugere que os pré-adolescentes do G1, aqueles que conversam em casa, podem estar desenvolvendo o que Mauss et al. (2007) chamaram de perfil mais adaptativo de experiência emocional. Em adultos, Mauss et al. verificaram que o grupo que obteve escores elevados em reavaliação cognitiva diante de uma situação que provocava raiva administrou a experiência afetiva com um custo psicofisiológico menor, medido pelas respostas cardiovasculares. Além disso, designar um significado não emocional ao evento estressor reduz seu impacto emocional fazendo a experiência subjetiva de desconforto da pessoa diminuir. Em consequência, cessa a urgência de autorregulação, o que por sua vez, permite que recursos cognitivos como a memória, fiquem disponíveis (Gross et al., 2006; Schore, 2001). Esse resultado mostra a importância das conversações em família para o manejo da raiva.

A ausência de diferenças significativas entre os dois grupos nos dois outros parâmetros de comparação, estimativa da duração das emoções e estratégias para regulá-las, levanta algumas questões. Em relação à habilidade para regular emoções, sabe-se que seu desenvolvimento é uma consequência da socialização, função exercida fundamentalmente pelos pais, mas que outros adultos no contexto familiar mais amplo e no contexto escolar também cumprem (Grusec, 2002). Estratégias de regulação menos eficazes foram pouco escolhidas (no grupo 1: apenas na regulação da raiva há duas respostas "não sei" e duas "vingar-se"; no grupo 2: na regulação da tristeza há 7 respostas "não sei" e na regulação da raiva, há 3 respostas "vingar-se"). Esses resultados mostram que pré-adolescentes que costumam e que não costumam conversar em casa desenvolveram habilidades para regular emoções, sugerindo que essa aprendizagem não se dá exclusivamente no contexto da conversação familiar, mas também na interação com outros adultos do ambiente social. Esse contexto interativo mais amplo teria a potencialidade de suprir lacunas do contexto familiar, funcionando como fator de proteção no desenvolvimento (Costa \& Bigras, 2007).

Apesar de não terem sido encontradas diferenças significativas entre os dois grupos nesses parâmetros, há características qualitativas que os distinguem. Em estimativa de duração da emoção, os pré-adolescentes do G1 preferiram utilizar as condições presentes na situação (e.g., até tirar o gesso; até o recreio acabar; até fazer a amiga pedir desculpas). Estimar a duração da emoção tendo por base uma condição presente na situação mostra que houve reflexão por parte desses pré-adolescentes acerca da situação de modo a extrair dela possibilidades para resolver o problema. Já no G2, a preferência por estimar a duração da emoção pelo critério temporal (tempo determinado) pode indicar que esses pré-adolescentes viveram experiências prévias bem- 
-sucedidas de autorregulação, o que lhes permitiria assegurar que em pouco tempo poderiam controlar a emoção. Gross e Thompson (2007), no entanto, mostram que a tendência das pessoas é superestimar a duração de suas respostas emocionais negativas para as mais variadas situações e não estimar que elas terão curta duração. A tendência de superestimar a própria habilidade para lidar com emoções é uma questão a ser investigada.

No que concerne às estratégias para regular emoções, as similaridades de escolha da estratégia pelos dois grupos indicam que esta é influenciada pela emoção a ser regulada. Essas similaridades também permitem vislumbrar o que podem ser características próprias da pré-adolescência que diferem daquelas da adolescência e que revelam maior proximidade com a fase final da infância. Para lidar com a tristeza, ao redor de um terço dos pré-adolescentes nos dois grupos optou pela estratégia distrair-se. A distração é o primeiro processo regulatório da atenção a aparecer no desenvolvimento e é utilizada vida afora quando não é possível modificar a situação (Gross \& Thompson, 2007). Em contraste, o uso de técnicas cognitivas, a segunda estratégia mais escolhida nos dois grupos, propicia que a situação geradora de emoção seja racionalizada com vistas ao seu controle. Assim, enquanto a distração afasta a pessoa da situação geradora da emoção sem alterá-la, as técnicas cognitivas agem sobre a situação. Resultado que corrobora os de Santos (2005), em que crianças de 6 a 10 anos optaram, de um modo geral, por distrair-se e que as mais velhas optaram por técnicas cognitivas; e está alinhado aos resultados de Cruvinel e Boruchovitch (2011), em que a estratégia mais frequente de crianças de 8 a 12 anos foi envolver-se em atividades prazerosas. Apesar da preferência pela distração, alguns pré-adolescentes do presente estudo empregaram técnicas cognitivas, utilizando habilidades cognitivas próprias do período da adolescência (Piaget, 1972), indicando que esse é um período de transição entre infância e adolescência em relação aos processos regulatórios.

Essa explicação de transição etária também pode ser usada para as estratégias empregadas na emoção raiva. Nos dois grupos, um terço dos pré-adolescentes optou por buscar ajuda de adultos. Estratégia que foi mais utilizada pelas crianças brasileiras de 5 a 9 anos na pesquisa de Dias et al. (2000). A busca por ajuda de adultos também pelos pré-adolescentes que não costumam conversar em casa (G2) mostra que eles não estão isolados. Essa necessidade de proximidade com os adultos, verificada nessa amostra, pode representar uma tendência de comportamento em famílias de classe média na atualidade, referida em Roazzi et al. (2011). Com relação à segunda escolha mais frequente, o G2 optou pela distração, enquanto um terço dos pré-adolescentes do G1 escolheu agir de modo altruísta. As opções "ajuda adulta" e "agir de modo altruísta" representam as normas sociais e mostram confiança na solução que os adultos oferecem para os problemas, o que reforça a importância do apoio dos adultos do ambiente social (Costa \& Bigras, 2007). A raiva, portanto, é uma emoção que pode mobilizar no pré-adolescente a necessidade de proximidade com os adultos e suas normas sociais.

Algumas considerações metodológicas são necessárias. A classificação original das estratégias de regulação, mesmo depois de adaptada, não permitiu discriminar entre respostas qualitativamente diferentes quando eram usadas estratégias mais sofisticadas (e.g., técnicas cognitivas). Em pesquisas futuras, sugere-se uma investigação qualitativa do uso de seleção de situação, mudança cognitiva (e.g., reavaliações cognitivas) e modulação de resposta. $\mathrm{O}$ instrumento qualitativo, criado por Cruvinel e Boruchovitch (2010), para investigar estratégias de regulação emocional em crianças de 8 a 11 anos pode ser uma alternativa. A escolha de histórias que mobilizem do mesmo modo meninos e meninas é outro desafio a considerar. Uma variante alternativa às histórias apresentadas aos pré-adolescentes seria solicitar que lembrassem uma situação em que sentiram determinada emoção e, então, fazer as perguntas sobre regulação emocional.

Ao longo do desenvolvimento, experiências desagradáveis que envolvem emoções como tristeza e raiva cumprem um importante papel para que a pessoa alcance estabilidade emocional, desde que o ambiente social possa responder adequadamente. Os resultados obtidos pelos pré-adolescentes que costumam conversar sobre experiências que envolvem raiva sugerem que esses tiveram mais oportunidades sistemáticas de treinar sua habilidade para avaliar esse tipo de experiência e aprender a lidar com essa emoção. O contexto da conversação familiar sobre experiências envolvendo raiva, portanto, se apresenta como uma resposta do ambiente que favorece um desenvolvimento saudável.

\section{Referências}

Bahls, S. C., \& Bahls, F. (2002). Depressão na adolescência: Características clínicas. Interação em Psicologia, 6, 49-57.

Baptista, M., \& Oliveira, A. (2004). Sintomatologia de depressão e suporte familiar em adolescentes: Um estudo de correlação. Revista Brasileira de Crescimento e Desenvolvimento Humano, 14, 58-67.

Benetti, S., Ramires, V. R., Schneider, A. C., Rodrigues, A. P., \& Tremarin, D. (2007). Adolescência e saúde mental: Revisão de artigos brasileiros publicados em periódicos nacionais. Caderno de Saúde Pública, 23, 1273-1282.

Bohanek, J., Marin, K., Fivush, R., \& Duke, M. (2006). Family narrative interaction and children's sense of self. Family Process, 45, 39-54.

Breinbauer, C., \& Maddaleno, M. (2005). Youth: Choices and change. Promoting healthy behaviors in adolescents. Scientific and Technical Publication $\mathrm{n}^{\circ}$ 594. Washington, DC: Pan American Health Organization.

Bruner, J. (1997). Atos de significação (2a ed., S. Costa, Trad.) Porto Alegre: Artes Médicas.

Burch, M., Austin, J., \& Bauer, P. (2004). Understanding the emotional past: relations between parent and child contributions in emotionally negative and nonnegative events. Journal of Experimental Child Psychology, 89, 276-297.

Calkins, S., \& Hill, A. (2007). Caregiver influences on emerging emotion regulation. In J. Gross (Ed.), Handbook of emotion regulation (pp. 229-248). New York: Guilford Press.

Costa, M., \& Bigras, M. (2007). Mecanismos pessoais e coletivos de proteção e promoção da qualidade de vida para a infância e adolescência. Ciência e Saúde Coletiva, 12(5), 1101-1109.

Cruvinel, M., \& Boruchovich, E. (2010). Regulação emocional: A construção de um instrumento e resultados iniciais. Psicologia em Estudo, 15, 537-545. 
Cruvinel, M., \& Boruchovich, E. (2011). Regulação emocional em crianças com e sem sintomas de depressão. Estudos de Psicologia, 16, 219-226.

Damasio, A. (2004). Em busca de Espinosa: Prazer e dor na ciência dos sentimentos. São Paulo: Companhia das Letras.

Dias, M. G., Vikan, A., \& Gravas, S. (2000). Tentativas de crianças em lidar com as emoções de raiva e de tristeza. Estudos de Psicologia (Natal), 5, 49-70.

Dunn, J., Bretherton, I., \& Munn, P. (1987). Conversations about feeling states between mothers and their young children. Developmental Psychology, 23, 132-139.

Fivush, R. (1991). The social construction of personal narratives. Merrill-Palmer Quartely, 37, 59-82.

Fivush, R. (2007). Maternal reminiscing style and children's developing understanding of self and emotion. Clinic Social Work Journal, 35, 37-46.

Fivush, R., \& Kuebli, J. (1997). Making everyday events emotional: The construal of emotion in parent-child conversations about past. In N. Stein, P. Ornstein, B. Tversky, \& C. Brainerd (Eds.), Memory for everyday and emotional events (pp. 239-266). New Jersey: Lawrence Erlbaum Associates.

Fivush, R., Haden, C., \& Reese, E. (2006). Elaborating on elaborations: Role of maternal reminiscing style in cognitive and socioemotional development. Child Development, 77, 1568-1588

Fivush, R., \& Sales, J. (2002). Children's memories of emotional events. In D. Reisberg, \& P. Hertel (Eds.), Memory and emotion (pp. 242-271). New York: Oxford University Press.

Fivush, R., \& Sales, J. (2006). Coping, attachment and mother-child narratives of stressfull events. Merrill-Palmer Quarterly, 52, 125-150.

Formiga, N. (2004). A explicação dos comportamentos desviantes a partir dos indicadores da relação familiar. Psicologia Argumento, 22, 45-52.

Formiga, N., Cavalcante, C., Araújo, T., Lima, S., \& Santana, R. (2007). Comportamento agressivo e busca de sensação em jovens. Psicologia Argumento, 25, 289-302.

Gross, J. (1998). The emerging field of emotion regulation: An integrative review. Review of General Psychology, 2, 271-299.

Gross, J., Richards, J., \& John, O. (2006). Emotion regulation in everyday life. In D. K. Snyder, J. A. Simpson, \& J. N. Hughes (Eds.). Emotion regulation in couples and families: pathways to dysfunction and health (pp. 13-35). Washington DC: American Psychological Association.

Gross, J., \& Thompson, R. (2007). Emotion regulation: Conceptual foundations. In J. Gross (Ed.), Handbook of emotion regulation (pp. 3-24). New York: Guilford Press.

Grusec, J. E. (2002). Parental socialization and children's acquisition of values. In M. H. Bornstein (Ed.), Handbook of parenting: Practical issues in parenting (Vol. 5, pp. 143-167). Mahwah, NJ: Lawrence Erlbaum Associates.

Harris, P., \& Lipian, M. (1989). Understanding emotion and experiencing emotion. In P. L. Harris, \& C. Saarni (Eds.), Children's understanding of emotion (pp. 241-258). New York: Cambridge University Press.

Macedo, L. S. R. (2011). Conversações sobre experiências envolvendo emoções no contexto familiar e o desenvolvimento de pré-adolescentes. (Tese de Doutorado não-publicada). Universidade Federal do Rio Grande do Sul, Porto Alegre.
Markus, H., \& Kitayama, S. (1991). Culture and the self: Implications for cognition, emotion and motivation. Psychological Review, 98, 224-253.

Mauss, I., Cook, C., Cheng, J., \& Gross, J. (2007). Individual differences in cognitive reappraisal: Experiential and physiological responses to an anger provocation. International Journal of Psychophysiology, 66, 116-124.

Oliveira, S. G., Dias, M. G., \& Roazzi, A. (2003). O lúdico e suas implicações nas estratégias de regulação das emoções em crianças hospitalizadas. Psicologia: Reflexão e Crítica, 16, $1-13$.

Pavarini, G., Loureiro, C., \& Souza, D. (2011). Compreensão de emoções, aceitação social de atributos comportamentais em crianças escolares. Psicologia: Reflexão e Crítica, 24, 135-143.

Piaget, J. (1972). Problemas de psicologia genética. Lisboa: Dom Quixote.

Reppold, C., \& Hutz, C. (2003). Prevalência de indicadores de depressão entre adolescentes no Rio Grande do Sul. Avaliação Psicológica, 2, 175-184.

Roazzi, A., Dias, M. G., Silva, J., Santos, L., \& Roazzi, M. (2011). O que é emoção? Em busca da organização estrutural do conceito de emoção em crianças. Psicologia: Reflexão $e$ Crítica, 24, 51-61.

Sales, J., \& Fivush, R. (2005). Social and emotional functions of mother-child reminiscing about stressful events. Social Cognition, 23, 70-90.

Sales, J., Fivush, R., Parker, J., \& Bahrick, L. (2005). Stressing memory: Long-term relations among children's stress, recall and psychological outcome following hurricane Andrew. Journal of Cognition and Development, 6, 529-545.

Santos, S. (2005). Raciocínio emocional e regulação afetiva numa perspectiva desenvolvimental na infância. Dissertação de Mestrado, Universidade Federal de Uberlândia, Uberlândia.

Schore, A. (2001). Effects of a secure attachment relationship on right brain development, affect regulation and infant mental health. Infant Mental Health Journal, 22(1-2), 7-66.

Shaffer, D., \& Kipp, K. (2009). Developmental psychology: Childhood and adolescence. Belmont, CA: Cengage Learning.

Sillars, A., Canary, D. J., \& Tafoya, M. (2004). Communication, conflict and the quality of family relationships. In A. Vangelisti (Ed.), Handbook of family communication (pp. 413-446). Mahwah, NJ: Lawrence Erlbaum Associates.

Soares, K., Almeida, N., Coutinho, O., \& Mari, J. (1999). Sintomas depressivos entre adolescentes e adultos de uma amostra populacional de três centros urbanos brasileiros: análise dos dados do Estudo Multicêntrico de Morbidade Psiquiátrica. Revista de Psiquiatria Clínica, 26, 218-224.

Wagner, A., Falcke, D. Silveira, L., \& Mosmann, C. (2002). A comunicação em famílias com filhos adolescentes. Psicologia em Estudo, 7, 75-80.

Recebido em 19.10.2011

Primeira decisão editorial em 02.05.2012

Versão final em 30.05.2012

Aceito em 18.06.2012 